\title{
BMJ Open Case fatality rate and associated factors in patients with 22q11 microdeletion syndrome: a retrospective cohort study
}

\author{
Gabriela M Repetto, ${ }^{1,2}$ M Luisa Guzmán, ${ }^{1}$ Iris Delgado, ${ }^{3}$ Hugo Loyola, ${ }^{4}$ \\ Mirta Palomares, ${ }^{5,6}$ Guillermo Lay-Son, ${ }^{1,2}$ Cecilia Vial, ${ }^{1}$ Felipe Benavides, ${ }^{1}$ \\ Karena Espinoza, ${ }^{1}$ Patricia Alvarez ${ }^{7}$
}

To cite: Repetto GM, Guzmán ML, Delgado I, et al. Case fatality rate and associated factors in patients with 22q11 microdeletion syndrome: a retrospective cohort study. BMJ Open 2014:4:e005041. doi:10.1136/bmjopen-2014005041

- Prepublication history for this paper is available online. To view these files please visit the journal online (http://dx.doi.org/10.1136/ bmjopen-2014-005041)

Received 11 February 2014 Revised 4 October 2014 Accepted 6 October 2014

CrossMark

For numbered affiliations see end of article.

Correspondence to Dr Gabriela M Repetto; grepetto@udd.cl

\section{ABSTRACT}

Objective: Chromosome 22q11.2 deletion is the most commonly occurring known microdeletion syndrome. Deaths related to the syndrome have been reported, but the magnitude of death has not been quantified. This study evaluated the deletion's impact on survival and its clinical manifestations in a large cohort of Chilean patients.

Design: Demographic and clinical data of individuals with 22q11 deletions diagnosed between 1998 and 2013 were collected from medical records and death certificates. Case fatality rate was calculated and compared with national vital statistics. OR with $95 \% \mathrm{Cl}$ analysis was used to assess the association between clinical manifestations and death.

Setting: Genetic services in tertiary care centres in Chile, following patients with 22q11.2 deletion.

Outcomes: Fatality rate and associated factors. Results: 59 of 419 patients (14.1\%) died during the study period at a median of 3.4 months (range 0 to 32 years of age). Factors associated with death included congenital heart disease (OR 5.27; $95 \% \mathrm{Cl} 2.06$ to $13.99 ; p<0.0001$ ), hypocalcaemia (OR $4.27 ; 95 \% \mathrm{Cl} 1.67$ to $11.15 ; p<0.002$ ) and airway malacia (OR $13.37 ; 95 \% \mathrm{Cl} 1.19$ to 110.51 ; $\mathrm{p}<0.002)$. Patients with deletions and defects such as tetralogy of Fallot with or without pulmonary atraesia, truncus arteriosus or ventricular septal defect, had a 2.6-fold to 4.6-fold higher death rate compared with nationwide reports for the same types of defects.

Conclusions: In this cohort, we observed a death rate of $14.1 \%$, implying that one in seven patients with 22q11 deletion died during the study period. Significant associations with cardiac defects, hypocalcaemia and airway malacia were observed. Furthermore, the death risk in patients with 22q11 deletion and cardiac defects exceeded the global figures observed in Chile for infants with structurally similar but apparently isolated anomalies. These observations indicate a need to identify patients who may require specific perioperative management to improve survival.
Strengths and limitations of this study

- The results are strengthened by the inclusion of a large group of patients with $22 q 11$ deletion, most of whom were followed for over a decade. The sample accounts for the majority of cases in the country, and the participants have had similar access to congenital heart defect diagnosis and repair since 2005 in the context of the National Health Care Reform in Chile.

- The main limitation of our study is that it relied on clinical recognition and confirmation of the deletion; therefore, severe cases with early mortality and undiagnosed cases were not included.

- We recognise that statistical analysis is also limited by partially complete data for some relevant clinical variables, such as calcium levels, airway anatomy, immune function and specific mode of death.

\section{INTRODUCTION}

Chromosome 22q11 microdeletion syndrome (22q11DS; MIM \#188400 and 192430) is the most commonly known microdeletion syndrome in humans, with an estimated incidence of 1 in 4000 live-births. ${ }^{1}$ It causes congenital heart disease (CHD), hypocalcaemia, cognitive disabilities and psychiatric disease, among other symptoms. ${ }^{1}$ Several authors have reported an increase in postoperative mortality in paediatric patients with CHD and 22q11DS compared with patients with non-syndromic $\mathrm{CHD} ;{ }^{2}{ }^{3}$ however, this association appears to be controversial and has not been observed by other authors. ${ }^{4-6}$ In addition, sudden death in adults with 22q11DS has also been described. $^{7}$ Given these findings, we sought to investigate survival and factors associated with death in a large cohort of Chilean patients having this syndrome.

\section{METHODS}

Patients with 22q11DS that was confirmed with fluorescence in situ hybridisation 
(FISH) (TUPLE 1 Probe, Abbott Molecular, Abbott Park, Illinois, USA) and/or multiplex ligation dependent probe amplification (MLPA) (SALSA MLPA P250 DiGeorge probe mix, MRC, Amsterdam, the Netherlands) in one of the six clinical cytogenetic laboratories that perform such testing in Chile between 1998 (when FISH testing was clinically introduced in the country) and 2013 were included in the study. The patients were identified at cardiology, cleft palate, genetics or developmental paediatrics clinics; through family support groups; and/or through periodic surveys to cytogenetics laboratories. Clinical and demographic data were collected from medical records, death certificates when pertinent and/or parental/patient interviews using a standardised questionnaire. Information was gathered retrospectively at the time of inclusion and prospectively thereafter. Living or deceased status in December 2013 was obtained for every participant through the National Civil and Information Registry (http://www.registrocivil.cl). This longitudinal cohort was recruited as part of consecutive research projects that aim to characterise the syndrome in Chile and identify the clinical, epidemiological and molecular risk factors for the development of individual features of the syndrome.

Cardiac anatomy was evaluated by a paediatric cardiologist using echocardiogram. Airway abnormalities were assessed with bronchoscopy performed by a paediatric pulmonologist, and malacia was defined as the collapse of at least $50 \%$ of the airway lumen during expiration, cough or spontaneous breathing or a $<3: 1$ ratio of cartilage to membranous wall area. ${ }^{8}$

The association of demographic features and clinical manifestations with death was evaluated using Fisher's exact test and ORs. Survival function was estimated using the Kaplan-Meier method. Significant differences in the survival functions of CHD and patients with non-CHD were evaluated with the log-rank test. For some clinical features, data were incomplete; therefore,

\begin{tabular}{lrc}
$\begin{array}{l}\text { Table } 1 \text { Causes of death according to the death } \\
\text { certificate }\end{array}$ & N & Per cent \\
\hline & 27 & 45.8 \\
Cardiac & 9 & 15.3 \\
Cardiac+respiratory failure & 6 & 10.2 \\
Cardiac+infectious & 2 & 3.4 \\
Cardiac+central nervous system anomaly & 1 & 1.7 \\
Cardiac+immunodeficiency & 1 & 1.7 \\
Cardiac+multisystem failure & 7 & 11.9 \\
Infection (pneumonia) or sepsis & 2 & 3.4 \\
Multisystem failure & 1 & 1.7 \\
Respiratory failure & 1 & 1.7 \\
Tracheobronchomalacia & 1 & 1.7 \\
Central nervous system anomaly & 1 & 1.7 \\
Unknown & 59 & 100.0 \\
Total & &
\end{tabular}

the statistical analysis included only patients with recorded data. As a reference, the results were compared with official case fatality statistics for CHD (International Classification of Diseases (ICD)-10, codes Q20-25) from hospital discharges in Chile for 20012011, the latter year being the most current nationwide information available at the time of writing. ${ }^{9} \mathrm{R}$ software $^{10}$ and SPSS V.20.0 (SPSS Inc, Chicago, Illinois, USA) were used for statistical analysis. A $p$ value $<0.05$ was considered statistically significant.

\section{RESULTS}

Of 430 known patients with postnatal diagnosis of the deletion, 419 consented to participate in the study. The participants included 198 males $(47.2 \%)$ and 221 females $(52.7 \%)$. Seventeen cases $(4 \%)$ had a parent with the deletion, but this prevalence is a clear underestimate because only those parents with features suggestive of the syndrome had undergone molecular testing due to insurance coverage limitations. Sixteen of them $(94 \%)$ were of maternal inheritance.

The median age of inclusion in the cohort was 12 years and ranged from 0 to 52 years. Fifty-nine (14.1\%) participants died during the 15-year study period (1998-2013). The median age at death was 3.4 months, with a minimum of 3 days and a maximum of 32.4 years. Only two patients died after 2 years of age: one at 9.9 years from septic shock and one at 32.4 years from pulmonary fibrosis and chronic respiratory insufficiency. Gender was not associated with death.

Table 1 lists the causes of death according to the death certificate. Cardiac causes were the most common; they were listed as the single cause of death in 27 patients $(45.8 \%)$ or in combination with other causes in $46(78 \%)$ patients. Infectious causes/immunodeficiency (sepsis, pneumonia or intra-abdominal source) were the second most common cause of death; they were listed as the single primary cause in seven patients $(11.9 \%)$ or in combination with other causes (usually cardiac) in 14 patients $(23.7 \%)$. The third most common cause of death was related to the respiratory system (respiratory failure, malacia) alone in 2 patients $(3.4 \%)$ or with other causes in 11 patients (18.6\%). Information on the mode of death was unavailable for most patients because this is not listed in death certificates.

Information about cardiac anatomy was available for 366 patients, corresponding to $87 \%$ of the total participants and $88.5 \%$ of the deceased. Of the 366 patients for whom cardiac anatomy information was available, 233 (63.7\%) had a CHD, and $133(36.3 \%)$ had a structurally normal heart and great vessels according to echocardiogram. The presence of cardiac anomalies was significantly associated with mortality; 46 patients with CHD (19.7\% of all patients with CHD) and 6 patients without (4.5\% of all patients without CHD) died during the study period (OR 5.27; 95\% CI 2.06 to 13.99; p<0.0001; table 2). 
Figure 1 compares Kaplan-Meier survival curves for the patients with and without CHD. The two patients who died after 2 years of age did not have CHD.

Information regarding cardiac surgery was available for 40 of the 46 deceased patients with known CHD (87\%). Of the 40 deceased patients with surgical information, 10 (25\%) died before operative repair, $3(7.5 \%)$ died during surgery and $27(67.5 \%)$ died after surgery. Patients with CHD who underwent surgical repair died at a median of 3.5 months of age (ranging from 11 days to 1.65 years of age). These deaths occurred at a median of 3.6 months after surgery, ranging from 1 day to 1.2 years. Those with CHD but no cardiac surgery died earlier, at a median of 0.2 months, ranging from 3 days to 3.7 months of age. The six patients without CHD died at a median of 4.7 months, ranging from 2.8 months to 32.4 years. In contrast, surgery data were available for 186 of 187 (99\%) of patients with CHD who were alive in December 2013. One hundred and forty $(75 \%)$ of these patients had undergone surgical repair during the study period, a proportion similar to that of the deceased group. The rest $(n=46)$ had pending surgeries or anatomical defects that did not require intervention (small atrial septal defects (ASDs) or ventricular septal defects (VSDs), right-sided aortic arch or aberrant subclavian arteries).

As a reference, infant mortality in Chile was approximately $8 / 1000$ live-births in the past decade. The fatality rate among hospital discharges for CHD was, on average, 5.4\% from 2001 to 2011. Eighty-six per cent of these deaths occurred in infants 1 year of age or younger, similar to the observation in the patients with 22q11 deletion. Since the deaths in both groups with CHD (general and 22q11DS) were concentrated in the first year of life, we compared case fatality rates for CHD hospital discharges in infants aged 1 year or younger from 2001 to 2011. We found that, on average, deaths were 3.6-fold higher in infants with 22q11DS compared with the rate reported for CHD nationwide (table 3).

The types of CHD in patients with 22q11DS tend to be more severe that those seen in apparently isolated cases, thus we compared the fatality rates for specific cardiac defects that are common in the syndrome. We found that in patients with 22q11DS, the case fatality rate was $50 \%$ among the 22 patients with truncus arteriosus, $32 \%$ for the 75 patients with tetralogy of Fallot, $41 \%$ for the subgroup of 24 infants with tetralogy of Fallot and pulmonary atraesia and $4.2 \%$ for the 48 patients with VSDs. In comparison, the case fatality rates for Chilean patients were 12\% for truncus arteriosus, 7\% for tetralogy of Fallot and $1.6 \%$ for VSDs. ${ }^{10}$ The latter figures are between 2.6-fold and 4.6-fold lower than the fatality rates observed for the same structural defects in 22q11DS patients.

Other factors associated with early death were a history of hypocalcaemia, measured as total calcium ( $\mathrm{p}=0.001$; OR $4.27 ; 95 \%$ CI 1.67 to 11.15$)$, and airway malacia demonstrated with bronchoscopy $(\mathrm{p}=0.043$; OR 13.375; $95 \%$ CI 1.190 to 110.514). However, information regarding timing of these diagnoses in relationship to surgeries or time of death was unavailable, and the data on airway abnormalities were additionally limited because endoscopic studies were only performed on symptomatic patients. Available information on immune and thyroid function was insufficient for analysis.

\section{DISCUSSION}

Our observations confirm that patients with 22q11DS have high death rates. We found that $14.1 \%$ of a large cohort of Chilean patients, or one in seven, died during the 15-year observation period. For the subgroup of patients with the deletion and CHD, the fatality rate was $19.7 \%$ or almost one in five patients. To the best of our knowledge, this is the largest series to report the case fatality rate and survival for this syndrome.

The majority of deaths occurred during the first year of life and was associated with the presence of CHD, particularly with severe cardiac defects that are common in this syndrome, such as tetralogy Fallot with pulmonary atraesia and truncus arteriosus. Right-sided heart failure, which is related to pulmonary vascular resistance, a common complication of these anomalies, has been proposed as an important contributor to mortality. ${ }^{3} 1112$

The diagnosis and treatment of CHD have universal coverage under Chilean Health Care Reform ${ }^{13}$ and paediatric cardiac surgeries have been performed in three national referral centres since 2005. Therefore, it is unlikely that differences in local clinical practices are the main cause of the high mortality in patients with 22q11DS, at least in the past 8 years. In fact, similar figures have been observed in comparisons of the fatality rates before and after the implementation of universal coverage for CHD diagnosis and treatment, which was guaranteed after the healthcare reform. Although overall national infant mortality for CHD decreased during this period ${ }^{10}$ the impact of universal coverage is less evident for children with severe and complex defects, such as those that are present in patients with 22q11DS. Indeed, we found that patients with 22q11DS had a higher overall fatality rate compared with the national statistics for patients with similar CHDs but without the syndrome; this discrepancy was evident for specific cardiac defects that are common in the syndrome, such as tetralogy of Fallot, truncus arteriosus and VSD. This finding suggests that even for similar anatomic defects, there are additional manifestations and, most likely, other pathophysiological features in patients with the syndrome, which may contribute to higher fatalities than is found in cases of apparently isolated defects. Among these features, we found that hypocalcaemia and airway abnormalities were also significant risk factors associated with early death. Low calcium levels are common in patients with the deletion, particularly during the cardiac postoperative period. Shen et $a l^{11}$ determined that the frequency of hypocalcaemia and the speed of calcium level decline after surgery are higher in patients with the deletion than in those 
Table 2 Univariate analysis of factors associated with mortality

\begin{tabular}{|c|c|c|c|c|c|}
\hline Characteristic & Deceased, n (\%) & Living, n (\%) & Total & $\begin{array}{l}\text { p Value } \\
\text { (Fisher's exact test) }\end{array}$ & $\begin{array}{l}\text { OR }(95 \% \mathrm{Cl}) \text { deceased } \\
\text { vs living patients }\end{array}$ \\
\hline & $59(14.1)$ & $360(85.8)$ & 419 & & \\
\hline \multicolumn{6}{|l|}{ Gender } \\
\hline Male & $26(44.1)$ & $172(47.8)$ & 198 & 0.67 & $0.87(0.48$ to 1.58$)$ \\
\hline Female & $33(55.9)$ & $188(52.2)$ & 221 & & \\
\hline \multicolumn{6}{|l|}{ Cardiac status } \\
\hline CHD data available & $52(14.2)$ & $314(85.8)$ & 366 & $<0.0001$ & 5.27 (2.06 to 13.99$)$ \\
\hline With CHD & $46(88.5)$ & $187(59.5)$ & 233 & & \\
\hline Normal cardiac anatomy & $6(11.5)$ & $127(40.5)$ & 133 & & \\
\hline \multicolumn{6}{|l|}{ Calcium status } \\
\hline Calcium data available & 24 & 253 & 277 & 0.001 & 4.27 (1.67 to 11.15$)$ \\
\hline Hypocalcaemia & $15(62.5)$ & $71(28.1)$ & 86 & & \\
\hline Normal calcium & 9 (37.5) & $182(71.2)$ & 191 & & \\
\hline \multicolumn{6}{|l|}{ Airway status } \\
\hline Airway data available & 6 & 246 & 252 & 0.0043 & 13.38 (1.19 to 110.51$)$ \\
\hline Malacia & $4(67)$ & $32(13)$ & 36 & & \\
\hline Normal airway & $2(33)$ & $214(87)$ & 216 & & \\
\hline
\end{tabular}

without and that this difference is associated with postsurgical complications. The authors did not show an association between hypocalcaemia and mortality, as we did in our study, but this difference may be related to their study's smaller sample size $(n=19)$. We did not have parathyroid hormone (PTH) levels for our patients, but other researchers have shown that postoperative hypocalcaemia is caused by a decreased PTH reserve. $^{11}{ }^{14}$ Our results emphasise a need to direct specific attention to the calcium levels of 22q11DS patients during the perioperative period.

Airway malacia was also a risk factor for lethality. This manifestation can be caused by the extrinsic compression by aberrant vessels or by intrinsic airway anomalies in 22q11DS patients. ${ }^{15}$ Its management often requires prolonged mechanical ventilation, which leads to an increased risk of infection that may also contribute to mortality. Future studies of the pathogenesis, early detection
Figure 1 Kaplan-Meier survival curves for 22q11Ds patients with or without congenital heart disease (CHD).

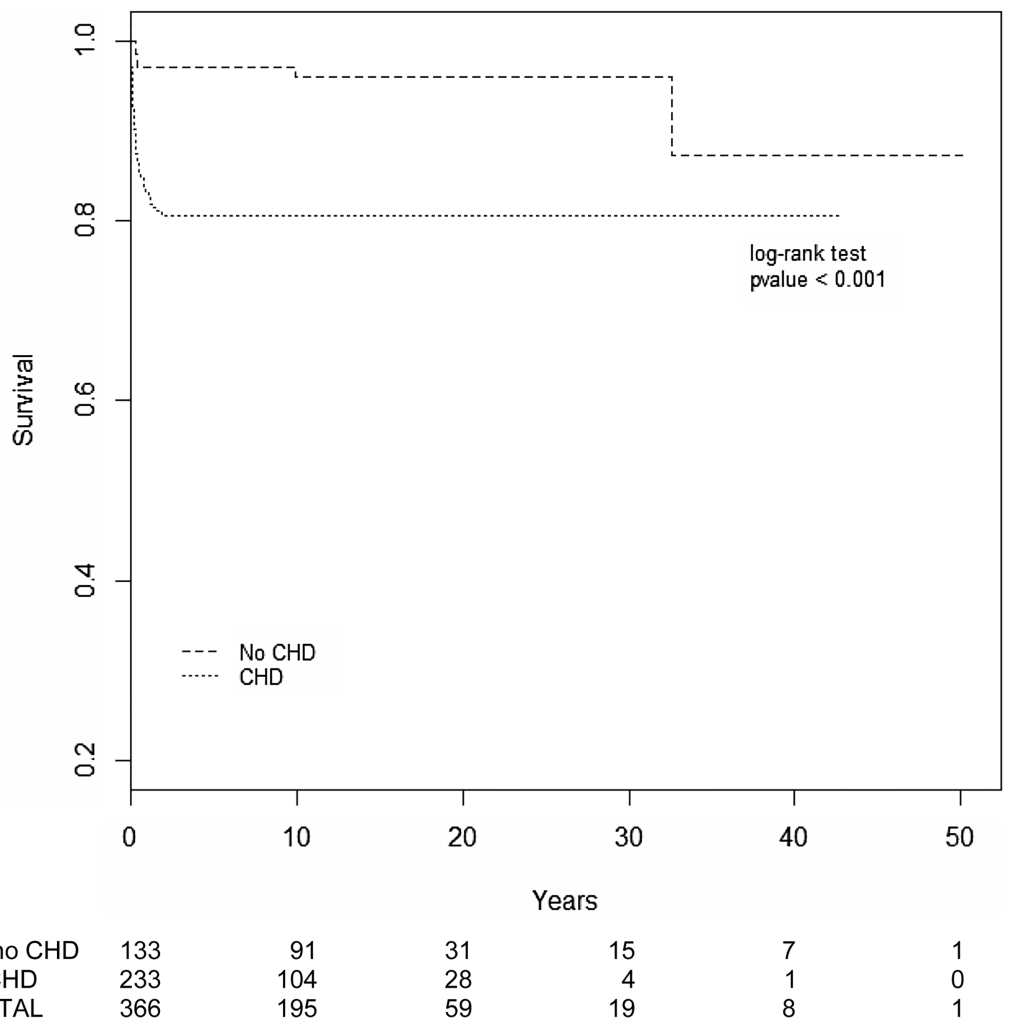


Table 3 Case fatality rates for hospital discharges in infants aged 1 year or younger with CHD: a comparison between patients with 22q11DS and the general national data (ICD 10 codes Q20-Q25)

\begin{tabular}{|c|c|c|c|}
\hline $\begin{array}{l}\text { Birth } \\
\text { year }\end{array}$ & $\begin{array}{l}\text { Case fatality } \\
\text { rates in } \\
22 q 11 D S \\
\text { patients with } \\
\text { CHD (per } 100 \\
\text { cases) }\end{array}$ & $\begin{array}{l}\text { General } \\
\text { case fatality } \\
\text { rate for } \\
\text { CHD in } \\
\text { Chile (per } \\
100 \text { cases) }^{9}\end{array}$ & $\begin{array}{l}\text { Ratio of case } \\
\text { fatality for } \\
\text { CHD in } \\
\text { 22q11DS/ } \\
\text { general } \\
\text { populations }\end{array}$ \\
\hline 2001 & 28.57 & 6.63 & 4.31 \\
\hline 2002 & 18.18 & 8.53 & 2.13 \\
\hline 2003 & 0.00 & 7.77 & 0.00 \\
\hline 2004 & 23.81 & 9.29 & 2.56 \\
\hline 2005 & 21.43 & 9.30 & 2.30 \\
\hline 2006 & 30.00 & 6.79 & 4.42 \\
\hline 2007 & 41.67 & 7.59 & 5.49 \\
\hline 2008 & 29.41 & 6.63 & 4.43 \\
\hline 2009 & 42.11 & 8.55 & 4.92 \\
\hline 2010 & 33.33 & 6.78 & 4.92 \\
\hline 2011 & 42.86 & 7.49 & 5.72 \\
\hline Average & 28.31 & 7.75 & 3.65 \\
\hline
\end{tabular}

and management strategies of airway anomalies in the syndrome will be relevant for treatment and prognosis.

This study is limited by its retrospective nature, partially complete clinical data, including a lack of accurate information about the timing of certain manifestations, such as hypocalcaemia, infections and mode of death, and biases related to the possible under-recognition of an unknown proportion of patients with the deletion. Nevertheless, in this relatively large series of patients, we found that the presence of 22q11DS adversely affects survival, particularly in individuals with CHD, hypocalcaemia and/or airway malacia. There may be a need for modified surgical techniques, timing and/or perioperative management of cardiac and extracardiac manifestations, as proposed by Carotti et al, ${ }^{16}$ to improve survival in 22q11DS patients and make it at least comparable to their non-syndromic counterparts, as is the current reality for patients with Down syndrome, for example. ${ }^{17}$

\section{Author affiliations}

${ }^{1}$ Facultad de Medicina, Center for Genetics and Genomics, Clinica Alemana Universidad del Desarrollo, Santiago, Chile

${ }^{2}$ Hospital Padre Hurtado, Santiago, Chile

${ }^{3}$ Facultad de Medicina, Centro de Epidemiología y Políticas de Salud, Clinica Alemana Universidad del Desarrollo, Santiago, Chile

${ }^{4}$ Facultad de Medicina, Clinica Alemana Universidad del Desarrollo, Santiago, Chile

${ }^{5}$ Hospital Dr. Luis Calvo Mackenna, Santiago, Chile

${ }^{6}$ Fundación Dr. Alfredo Gantz Mann, Santiago, Chile

${ }^{7}$ Hospital Dr. Roberto del Rio, Santiago, Chile

Acknowledgements The authors thank Baltica Cabieses, PhD, for her helpful review of the manuscript and Ms Megan Bunnell for language editing.

Contributors GMR and MLG participated in the study concept and design. MLG, MP, GL-S and PA participated in data acquisition. ID and HL performed the statistical analysis. GMR, GL-S, CV and PA participated in the drafting and critical revision of the manuscript for important intellectual content. FB and KE provided administrative, technical and material support. GMR obtained funding and participated in overall study supervision. All of the authors critically reviewed and approved the final version of the manuscript.

Funding This work was supported by FONDECYT-Chile grants \# 1100131 and 1130392.

Competing interests None.

Ethics approval The study was approved by the institutional review boards of the participating centres (Facultad de Medicina, Clinica Alemana Universidad del Desarrollo; Hospital Padre Hurtado; Hospital Calvo Mackenna, Fundación Gantz; Hospital Roberto del Rio), and the patients or their parents gave written informed consent.

Provenance and peer review Not commissioned; externally peer reviewed.

Data sharing statement No additional data are available.

Open Access This is an Open Access article distributed in accordance with the Creative Commons Attribution Non Commercial (CC BY-NC 3.0) license, which permits others to distribute, remix, adapt, build upon this work noncommercially, and license their derivative works on different terms, provided the original work is properly cited and the use is non-commercial. See: http:// creativecommons.org/licenses/by-nc/3.0/

\section{REFERENCES}

1. Bassett AS, McDonald-McGinn DM, Devriendt K, et al:; International 22q11.2 Deletion Syndrome Consortium. Practical guidelines for managing patients with 22q11.2 deletion syndrome. J Pediatr 2011:159:332-9.

2. Carotti A, Albanese SB, Filippelli S, et al. Determinants of outcome after surgical treatment of pulmonary atresia with ventricular septal defect and major aortopulmonary collateral arteries. J Thorac Cardiovasc Surg 2010;140:1092-103.

3. Chen MY, Chiu SN, Wang JK, et al. Genetic syndromes and outcome after surgical repair of pulmonary atresia and ventricular septal defect. Ann Thorac Surg 2012;94:1627-33.

4. Doell C, Bernet V, Molinari L, et al. Children with genetic disorders undergoing open-heart surgery: are they at increased risk for postoperative complications? Pediatr Crit Care Med 2011;12:539-44.

5. McDonald R, Dodgen A, Goyal S, et al. Impact of 22q11.2 deletion on the postoperative course of children after cardiac surgery. Pediatr Cardiol 2013;34:341-7.

6. Mercer-Rosa L, Pinto N, Yang W, et al. 22q11.2 Deletion syndrome is associated with perioperative outcome in tetralogy of Fallot. $J$ Thorac Cardiovasc Surg 2013;146:868-73.

7. Bassett AS, Chow EW, Husted J, et al. Premature death in adults with 22q11.2 deletion syndrome. J Med Genet 2009;46:324-30.

8. Schroth M, Green C. Persistent and recurrent pneumonia. In: Holinger L, Lusk R, Green C. Pediatric laryngology and bronchoesophagology. Lippincott-Raven, 1997:263-73.

9. Ministerio de Salud de Chile, Department of Health Statistics and Information (DEIS). Deaths and Hospitals Discharges Database Chile 2001-2011. http://www.deis.cl/?page id=3487 (accessed Jul 2014).

10. R Core Team 2013. R: A language and environment for statistical computing. R Foundation for Statistical Computing, Vienna, Austria. http://www.R-project.org/ (accessed Dec 2013).

11. Shen L, Gu H, Wang D, et al. Influence of chromosome $22 q 11.2$ microdeletion on postoperative calcium level after cardiac-correction surgery. Pediatr Cardiol 2011;32:904-9.

12. Mahle WT. Invited commentary. Ann Thorac Surg 2012;94:1633-4.

13. Bastías G, Pantoja T, Leisewitz T, et al. Health care reform in Chile. CMAJ 2008;179:1289-9.

14. Cuneo BF, Langman $\mathrm{CB}$, Ilbawi MN, et al. Latent hypoparathyroidism in children with conotruncal cardiac defects. Circulation 1996;93:1702-8.

15. Yamagishi $\mathrm{H}$, Maeda J, Higuchi M, et al. Bronchomalacia associated with pulmonary atresia, ventricular septal defect and major aortopulmonary collateral arteries, and chromosome $22 q 11.2$ deletion. Clin Genet 2002;62:214-19.

16. Carotti A, Digilio MC, Piacentini G, et al. Cardiac defects and results of cardiac surgery in 22q11.2 deletion syndrome. Dev Disabil Res Rev 2008;14:35-42

17. Fudge JC Jr, Li S, Jaggers J, et al. Congenital heart surgery outcomes in down syndrome: analysis of a national clinical database. Pediatrics 2010;126:315-22. 